\title{
Expressive Writing Effects on Body Image: Symptomatic versus Asymptomatic Women
}

\author{
Jondell Lafont, Crystal D. Oberle* \\ Department of Psychology, Texas State University, San Marcos, USA \\ Email: ${ }^{*}$ oberle@txstate.edu
}

Received 12 February 2014; revised 13 March 2014; accepted 12 April 2014

Copyright (C) 2014 by authors and Scientific Research Publishing Inc.

This work is licensed under the Creative Commons Attribution International License (CC BY). http://creativecommons.org/licenses/by/4.0/

(c) (7) Open Access

\begin{abstract}
This study investigated the effects of expressive writing on body image of women varying in eating disorder symptomatology. Ninety-two female undergraduates were randomly assigned to the writing topic conditions: traumatic events, body image, and room description. At three times (before, immediately after, and one month after the two-week intervention), participants selected from among nine figures (a) the figure deemed closest to their current figure, (b) the figure deemed closest to the ideal figure, and (c) the figure deemed closest to the figure that men prefer. The current figure ratings decreased after the writing intervention for the high-symptom group but not the low-symptom group. The ideal and male-preferred figure ratings were not affected by the intervention and did not differ between the symptom level groups. Based on the first finding, writing may improve body image perceptions in women with an already distorted body image.
\end{abstract}

\section{Keywords}

\section{Expressive Writing, Body Image, Eating Disorders, Figure Ratings}

\section{Introduction}

Misperception or distortion of body image is so often associated with eating disorders that the American Psychiatric Association (2000) includes “a disturbance in perception of body shape and weight” (p. 583) as an essential feature of anorexia and bulimia. Body image distortion includes perceptual distortion of one's body and negative feelings towards one's body, which are separate but related factors (Gray, 1977). Women often see themselves as larger, and this misperception leads to negative feelings about their body image.

Using silhouette figures that were developed by Stunkard, Sorensen, and Schulsinger (1983) to determine perceptions of body image, many researchers have examined the discrepancy between what women see as their

*Corresponding author. 
current figure and what they see as the ideal female figure. Three predominant results have been found in this research. First, women, regardless of weight, believe that thin female figures are more attractive than normal or overweight female figures (Fallon \& Rozin, 1985; Lokken, Ferraro, Kirchner, \& Bowling, 2003; Rand \& Wright, 2000; Rozin \& Fallon, 1988). Second, women, regardless of weight, believe that their current figure is bigger than the ideal, judging themselves to be overweight when comparing their current figure to their ideal figure (Fallon \& Rozin, 1985; Lokken et al., 2003; Rozin \& Fallon, 1988). Third, women believe that men prefer a thinner figure than men actually do (Bergstrom, Neighbors, \& Lewis, 2004; Fallon \& Rozin, 1985; Rozin \& Fallon, 1988). These distorted beliefs (that thinner figures are more ideal, that their figure is larger than the ideal, and that men prefer thinner figures) likely lead to dissatisfaction in women, which then leads to dieting. Bergstrom et al. (2004) add to these findings by stating that dieters actually do have more distorted body perceptions than non-dieters and that women with eating disorders have more distorted body perceptions than the general population. Thus, these distorted beliefs can eventually lead to development of an eating disorder.

Past research also indicates that expressive writing has helped individuals with a variety of psychological and physical problems. Over 20 years ago, the first expressive writing study was conducted by Pennebaker and Beall (as cited in Smyth \& Pennebaker, 2008), and participants who wrote about their emotions for 15 minutes on four consecutive days had improved health over the next few months when compared to a control group who wrote about superficial topics. Since then, over 200 expressive writing studies have been conducted, with no two studies using the same expressive writing "recipe" (Smyth \& Pennebaker, 2008). It has been found that sometimes this paradigm works and other times, it does not; however, since no two studies have been exactly alike, it is difficult to say why it works sometimes and does not work at other times.

Research reveals that writing about traumatic experiences has positive effects on physical and psychological health, such as decreased levels of distress in those who have suffered a trauma or loss (Kuiken, Dunn, \& Loverso, 2008); increased optimism about finding a new job in those who had recently lost a job (Spera, Buhfreind, \& Pennebaker, 1994); decreased depression, anxiety, and stress (Graf, Gaudiano, \& Geller, 2008; Sloan, Feinstein, \& Marx, 2009; Sloan, Marx, Epstein, \& Dobbs, 2008; Smyth, Hockemeyer, \& Tulloch, 2008); improved psychosocial functioning in homosexual men (Pachankis \& Goldfried, 2010); improved working memory capacity (Klein \& Boals, 2001; Yogo \& Fujihara, 2008); improved romantic relationships (Eels, 2006; Slatcher \& Pennebaker, 2006); fewer doctor visits (Pennebaker, Colder, \& Sharp, 1990; Pennebaker, Kiecolt-Glaser, \& Glaser, 1988); and lowered blood pressure (Pennebaker, Hughes, \& O’Heeron, 1987). Expressive writing has also been beneficial for cancer patients, such that female patients with low levels of emotional support report fewer intrusive thoughts (Low, Stanton, Bower, \& Gyllenhammer, 2010), and female patients report decreased distress and depression levels and higher levels of positive meaning in life (Kallay \& Baban, 2008).

Only a handful of researchers have used expressive writing interventions in an attempt to improve body image. Some researchers conducted research on individuals with eating disorders (Hiltunen, 2008; Schmidt, Bone, Hems, Lessem, \& Treasure, 2002), whereas others conducted research on university students (Earnhardt, Martz, Ballard, \& Curtin, 2002; Frayne \&Wade, 2006; Grasso, 2007). Although most researchers used both a control group and an experimental group, their writing tasks differed. Frayne and Wade (2006) had the experimental group write about past trauma and the control group write about future planning; Earnhardt et al. (2002) had the experimental group write about body image and the control group write about their room; Grasso (2007) had the experimental group write about their weight, shape, appearance, and other physical characteristics and the control group write about stress related to college; and Hiltunen (2008) had the experimental group write about an upsetting experience and the control group write about their favorite distraction. Only one group of researchers did not use a control and experimental group; instead, they had individuals with bulimia and binge-eating disorder write about stressful events but had individuals with anorexia reflect on their attachment relationships (Schmidt et al., 2002).

While past research has shown expressive writing to be much more therapeutic than factual writing for individuals with a variety of physical and psychological problems (Eels, 2006; Graf et al., 2008; Kallay \& Baban, 2008; Klein \& Boals, 2001; Kuiken et al., 2008; Low et al., 2010; Pachankis \& Goldfried, 2010; Pennebake et al., 1990; Pennebaker et al., 1987; Pennebaker et al., 1988; Slatcher \& Pennebaker, 2006; Sloan et al., 2009; Sloan et al., 2008; Smyth et al., 2008; Sper et al., 1994; Yogo \& Fujihara, 2008), the current literature does not suggest that the same is true for body image and eating disorder symptoms. In particular, most researchers found that both of their writing groups experienced an equivalent increase in mood (Earnhardt et al., 2002; Hiltunen, 2008), improvement in body image (Earnhardt et al., 2002; Grasso, 2007), and decrease in disordered eating 
(Earnhardt et al., 2002; Grasso, 2007; Hiltunen, 2008). However, Frayne and Wade (2006) found that the control group who wrote about future planning experienced greater reduction in disordered eating and ineffectiveness (feelings of inadequacy, insecurity, worthlessness, and lack of control) at the 10-week follow up than the experimental group who wrote about a traumatic event. Frayne and Wade (2006) attributed these reductions to the idea that the individuals who wrote about future planning probably felt more control over valued outcomes and that future planning may aid in the development of future coping tasks. These results are opposite of what would be expected based on past expressive writing research but still suggest that any type of writing may help. Yet, Grasso (2007) found that the group who wrote about body image self-reported that their expressive writing impacted their body image in a more positive way than the group who wrote about college stress.

Research regarding writing interventions for body image and eating disorder symptomatology has not shown the same results as previous research regarding expressive writing interventions for people with psychological and physical problems. In most of this research (Earnhardt et al., 2002; Frayne \& Wade, 2006; Grasso, 2007; Hiltunen, 2008), groups, regardless of whether they engaged in expressive or factual writing, seemed to improve. However, this research has been limited and many different methods have been used. No two researchers used the same writing tasks, and some researchers used university students, while other researchers used individuals with eating disorders.

The current study added to this body of literature by including three different writing tasks (writing about body image, writing about a traumatic event, and writing about a room) in two different groups of women (high symptomatology and low symptomatology). The primary research questions addressed (a) whether women who are asymptomatic differ from women who are symptomatic in how they respond on a body image questionnaire before writing, (b) whether type of writing affects how these two groups of women respond on a body image questionnaire immediately after writing, and (c) whether type of writing affects how these two groups of women respond on a body image questionnaire one month later.

\section{Method}

\subsection{Participants}

Participants included 92 women, recruited from undergraduate psychology courses at Texas State University. With consent of the instructors, participants received extra credit for their participation. In addition, participants who completed all phases of the experiment had their name put into a drawing with a chance of winning $\$ 500$. Given how many participants were needed for this study and given the time commitment that it required (five research sessions in the lab), these incentives were deemed necessary to encourage participation. Participants had a mean age $( \pm$ SD) of $19.15 \pm 1.74$ years and a self-reported body mass index (BMI) of $23.39 \pm 4.78$. Most participants (56.5\%) were Caucasian, 33.7\% were Hispanic, 6.5\% were African American, $2.2 \%$ were Asian American, and $1.1 \%$ were American Indian. Based on a median (7) split of the scores for the eating disorder inventory described below, participants were separated into symptom groups: $54.3 \%$ comprised the low symptomatology group, and $45.7 \%$ comprised the high symptomatology group. Using a random number generator, participants were assigned to the writing groups: $40.2 \%$ wrote about their body image, $30.4 \%$ wrote about a traumatic event, and $29.3 \%$ were in the control group and wrote about the rooms of their home.

Of the 92 participants, 11 did not complete the study. Five of them were in the body-image condition, one was in the traumatic-event condition, and five were in the room-control condition; this difference was not statistically significant, $\chi^{2}=2.91, p=.23$. In addition, the completers and non-completers did not significantly differ on BMI, eating disorder symptomatology score, or initial figure ratings (see Table 1).

\subsection{Materials and Procedure}

Participants were asked to come to a lab in the psychology building at Texas State University to participate in the study. Upon hearing a brief description of the study and signing a consent form, participants completed the 26-question Eating Attitudes Test (EAT-26; Garner \& Garfinkel, 1979), a questionnaire that asks about extreme dietary restrictions and dieting behavior, binging, vomiting, laxative abuse, and other symptoms of eating disorders. The EAT-26 has been shown to be internally consistent with a Cronbach's alpha of .85 (Siervo, Boschi, Papa, Bellini, \& Falconi, 2005), and it has been validated with anorexic patients and with nonclinical individuals at risk of developing eating disorders (Button \& Whitehouse, 1981; Johnson-Sabine, Wood, Mann, \&Wakeling, 
Table 1. Differences between completers and non-completers.

\begin{tabular}{|c|c|c|c|c|}
\hline & \multicolumn{2}{|c|}{$M(S D)$} & \multirow[b]{2}{*}{$t$} & \multirow[b]{2}{*}{$p$} \\
\hline & Completers & Non-completers & & \\
\hline BMI & $23.47(4.87)$ & $22.83(4.21)$ & 0.41 & .68 \\
\hline Eat-26 score & $9.75(8.33)$ & $10.09(7.16)$ & 0.13 & .90 \\
\hline Rating of ideal figure & $3.34(0.70)$ & $3.09(0.70)$ & 1.11 & .27 \\
\hline Rating of current figure & $4.17(1.22)$ & $4.00(1.00)$ & 0.43 & .67 \\
\hline Rating of figure preferred by men & $3.18(0.63)$ & $3.27(0.65)$ & 0.46 & .65 \\
\hline
\end{tabular}

Note: Ratings in this table are those that were completed before the writing intervention.

1985; Thompson \& Schwartz, 1982; Williams, Schaefer, Shisslak, Gronwaldt, \& Comerci, 1986).

After completing the EAT-26, participants completed the body image questionnaire (Pulvers et al., 2004). For the rating of the ideal figure, participants selected one of nine figures (that gradually change from very thin to very obese), which they believe represents the ideal figure. Individual scores ranged from 1 to 9, with lower numbers representing thinner figures deemed as the ideal. For the rating of the current figure, participants selected one of these same nine figures, which they believed is closest to their current figure. For the rating of the figure that women think men most prefer, participants selected one of these same nine figures, which they believed men would find most attractive. Pulvers et al.'s (2004) silhouette figures are more humanlike and are more representative of all races than previously used figures, and these researchers validated the instrument with findings of positive correlations between participants' ratings of their own figures and both their BMI and observers' ratings of the participants' figures.

Participants from each group were randomly assigned to one of three writing conditions: body image writing, traumatic event writing, or room writing. Immediately after completing the body image questionnaire, participants spent 30 minutes writing about their designated topic. Over the next two weeks, participants were asked to return to the lab on three non-consecutive days to continue the writing task. On each of these days, participants again spent 30 minutes writing about their designated topic. After the last writing session, participants completed the body image questionnaire for a second time. Finally, participants were asked to return to the lab one month later to complete the body image questionnaire one final time, after which participants were completely debriefed about the study and expected results.

\section{Results}

Three mixed-design $3 \times 2 \times 2$ ANCOVAs (one for each dependent variable: ideal figure, current figure, and figure that men find most attractive) were conducted to determine the main effects and the interactions. For all analyses, the between-subjects factors were writing condition (body image, traumatic event, and room control) and symptom group (low symptomatology and high symptomatology), and BMI was included as a covariate.

Regarding participants' ratings of the figure that they deemed to be the ideal figure, the descriptive statistics are provided in Table 2, and the results of the ANCOVA analysis are presented in Table 3. As may be seen from the latter table, none of the main effects and none of the interactions were significant.

Regarding participants' ratings of the figure that they deemed to be closest to their current figure, the descriptive statistics are provided in Table 4, and the ANCOVA results are presented in Table 5. There was a near-significant $(p=.054)$ interaction between time and the participants' symptom level. The rating for current figure decreased from Time 1 (before intervention) to Time 2 (immediately after intervention) and from Time 1 to Time 3 (one month later) for the high symptom group only.

Regarding participants' ratings of the figure they deemed to be the figure that men find most attractive, the descriptive statistics are provided in Table 6, and the results of the ANCOVA analysis are presented in Table 7. As may be seen from the latter table, these ratings were significantly lower for the high-symptom group than for the low-symptom group. Thus, those women with greater symptoms of eating disorders were more likely to believe that men preferred a thinner figure. However, as with the ratings of the figure they deemed to be ideal, none of the other main effects and none of the interactions were significant.

\section{Discussion}

This research compared body image perceptions between women who are symptomatic but not clinically diag- 
Table 2. Mean ratings of figure deemed as ideal figure.

\begin{tabular}{ccccc}
\hline & \multicolumn{3}{c}{ Low Symptom Level } & High Symptom Level \\
\hline Intervention & $n$ & $M(\mathrm{SD})$ & $n$ & $M(\mathrm{SD})$ \\
\hline Body image & 18 & Before intervention & $3.23(0.83)$ \\
Traumatic event & 15 & $3.28(0.83)$ & 13 & $3.22(0.67)$ \\
Room control & 12 & $3.47(0.64)$ & 12 & $3.55(0.60)$ \\
& & $3.58(0.51)$ & 10 & $3.31(0.63)$ \\
Body image & 18 & Immediately after intervention & & $2.83(0.58)$ \\
Traumatic event & 15 & $3.36(0.68)$ & 13 & $3.40(0.52)$ \\
Room control & 12 & $3.37(0.48)$ & 10 & $3.31(0.75)$ \\
& & $3.25(0.45)$ & & $2.75(0.62)$ \\
Body image & 18 & One month after intervention & 13 & $3.45(0.50)$ \\
Traumatic event & 15 & $3.50(0.71)$ & 12 & 10 \\
Room control & 12 & $3.50(0.73)$ & & \\
\hline
\end{tabular}

Table 3. ANCOVA for ratings of figure deemed as ideal figure.

\begin{tabular}{|c|c|c|c|c|}
\hline & $d f$ & $F$ & $p$ & $\eta^{2}$ \\
\hline Covariate: Body mass index & 1 & 3.81 & .055 & .050 \\
\hline Time (T) & 2 & 0.08 & .925 & .001 \\
\hline Writing condition (WC) & 2 & 2.18 & .120 & .056 \\
\hline Eating disorder symptom level (EDSL) & 1 & 3.22 & .077 & .042 \\
\hline $\mathrm{T} \times \mathrm{WC}$ & 4 & 1.52 & .201 & .040 \\
\hline $\mathrm{T} \times \mathrm{EDSL}$ & 2 & 0.98 & .379 & .013 \\
\hline WC $\times$ EDSL & 2 & 1.65 & .199 & .043 \\
\hline $\mathrm{T} \times \mathrm{WC} \times \mathrm{EDSL}$ & 4 & 0.28 & .888 & .008 \\
\hline Within-group error for time & 146 & $(.13)$ & & \\
\hline Within-group error for between variables & 73 & $(.32)$ & & \\
\hline
\end{tabular}

Note: Values in parentheses are mean square errors.

Table 4. Mean ratings of figure deemed closest to participant.

\begin{tabular}{|c|c|c|c|c|}
\hline \multirow[b]{2}{*}{ Intervention } & \multicolumn{2}{|c|}{ Low Symptom Level } & \multicolumn{2}{|c|}{ High Symptom Level } \\
\hline & $n$ & $M(\mathrm{SD})$ & $n$ & $M(\mathrm{SD})$ \\
\hline \multicolumn{5}{|c|}{ Before intervention } \\
\hline Body image & 18 & $3.78(0.65)$ & 13 & $4.08(0.86)$ \\
\hline Traumatic event & 15 & $4.40(1.92)$ & 12 & $4.13(1.25)$ \\
\hline Room control & 12 & $4.08(1.24)$ & 10 & $4.70(1.06)$ \\
\hline \multicolumn{5}{|c|}{ Immediately after intervention } \\
\hline Body image & 18 & $3.75(0.62)$ & 13 & $3.81(0.80)$ \\
\hline Traumatic event & 15 & $4.47(1.85)$ & 12 & $3.83(1.17)$ \\
\hline Room control & 12 & 3.83 (1.19) & 10 & $4.30(0.82)$ \\
\hline \multicolumn{5}{|c|}{ One month after intervention } \\
\hline Body image & 18 & $3.67(0.57)$ & 13 & $3.85(0.80)$ \\
\hline Traumatic event & 15 & $4.53(1.85)$ & 12 & $3.96(1.36)$ \\
\hline Room control & 12 & $3.92(1.08)$ & 10 & $4.10(0.74)$ \\
\hline
\end{tabular}

nosed with an eating disorder and women who are asymptomatic. By examining the ratings of the ideal figure, current figure, and figure deemed as the one that men prefer, this research was able to determine if an expressive writing intervention could affect body image in women with varying levels of eating disorder symptomatology. 
Table 5. ANCOVA for ratings of figure deemed closest to participant.

\begin{tabular}{|c|c|c|c|c|}
\hline & $d f$ & $F$ & $p$ & $\eta^{2}$ \\
\hline Covariate: Body mass index & 1 & 144.71 & .000 & .665 \\
\hline Time (T) & 2 & 0.93 & .398 & .013 \\
\hline Writing condition (WC) & 2 & 0.09 & .907 & .003 \\
\hline Eating disorder symptom level (EDSL) & 1 & 0.07 & .796 & .001 \\
\hline $\mathrm{T} \times \mathrm{WC}$ & 4 & 1.44 & .225 & .038 \\
\hline $\mathrm{T} \times \mathrm{EDSL}$ & 2 & 2.97 & .054 & .039 \\
\hline WC $\times$ EDSL & 2 & 0.31 & .731 & .008 \\
\hline $\mathrm{T} \times \mathrm{WC} \times \mathrm{EDSL}$ & 4 & 0.72 & .580 & .019 \\
\hline Within-group error for time & 146 & $(.15)$ & & \\
\hline Within-group error for between variables & 73 & $(.44)$ & & \\
\hline
\end{tabular}

Note: Values in parentheses are mean square errors.

Table 6. Mean ratings of figure deemed as the one men prefer.

\begin{tabular}{ccccc}
\hline & \multicolumn{3}{c}{ Low Symptom Level } & High Symptom Level \\
\hline Intervention & $n$ & $M(\mathrm{SD})$ & & $M(\mathrm{SD})$ \\
\hline Body image & 18 & Before intervention & & $2.92(0.76)$ \\
Traumatic event & 15 & $3.28(0.67)$ & 13 & $3.17(0.58)$ \\
Room control & 12 & $3.30(0.70)$ & 12 & $3.10(0.57)$ \\
& & $3.25(0.45)$ & 10 & $2.92(0.76)$ \\
Body image & 18 & Immediately after intervention & & $2.92(0.47)$ \\
Traumatic event & 15 & $3.25(0.65)$ & 13 & $3.00(0.67)$ \\
Room control & 12 & $3.23(0.56)$ & 12 & $2.92(0.64)$ \\
& & $3.17(0.39)$ & 10 & $3.00(0.43)$ \\
Body image & 18 & One month after intervention & 13 & $3.05(0.50)$ \\
Traumatic event & 15 & $3.31(0.62)$ & 12 & 10 \\
Room control & 12 & $3.27(0.62)$ & & \\
\hline
\end{tabular}

Table 7. ANCOVA for ratings of figure deemed as the one men prefer.

\begin{tabular}{|c|c|c|c|c|}
\hline & $d f$ & $F$ & $p$ & $\eta^{2}$ \\
\hline Covariate: Body mass index & 1 & 0.03 & .856 & .000 \\
\hline Time $(\mathrm{T})$ & 2 & 0.06 & .946 & .001 \\
\hline Writing condition (WC) & 2 & 0.06 & .936 & .002 \\
\hline Eating disorder symptom level (EDSL) & 1 & 4.01 & .049 & .052 \\
\hline Tx WC & 4 & 0.48 & .752 & .013 \\
\hline $\mathrm{T} \times \mathrm{EDSL}$ & 2 & 0.32 & .724 & .004 \\
\hline WC $\times$ EDSL & 2 & 0.18 & .840 & .005 \\
\hline T x WC x EDSL & 4 & 0.25 & .908 & .007 \\
\hline Within-group error for time & 146 & $(.08)$ & & \\
\hline Within-group error for between variables & 73 & $(.31)$ & & \\
\hline
\end{tabular}

Note: Values in parentheses are mean square errors.

In this study, there were no significant changes in the mean ratings of the ideal figure and the figure deemed as the one that men would prefer. The reason that these figure ratings were not affected by the writing intervention could be that the idea of what is considered ideal and beautiful by both men and women is so ingrained in us that it is difficult to change. The media bombards consumers with images of the "ideal woman" and promises that by using a certain product any "normal" woman can meet that standard. Straub (2007) states that the latest 
ideal is constantly reinforced by media images, and the media's influence of establishing role models is undeniable. So, the fact that the mean rating of the ideal figure and the mean rating of the figure deemed as the one that men would most prefer did not significantly change is not surprising. The ideas of ideal are so deep-rooted in today's women that it may require much more than just an expressive writing task to change them.

Support did emerge for the research questions pertaining to the rating of women's current figure. The mean rating for the current figure decreased from before the writing task to immediately after the writing task, as well as from before the writing task to one month later for the group with high eating disorder symptomatology. These findings show that the writing intervention had long lasting effects. However, for the group with low eating disorder symptoms, the current figure rating decreased from before the writing task to immediately after the writing task but showed no change from before the intervention to one month later. The fact that the mean rating of the current figure decreased from pre-intervention to post-intervention to one month later in the high-symptom group, regardless of writing group is not surprising, considering past research on expressive writing and body image (Earnhardt et al., 2002; Frayne \& Wade, 2006; Grasso, 2007; Hiltunen, 2008). These past researchers have also found that regardless of writing group, body image improves.

It is difficult to say exactly why something as simple as a writing task could produce such long lasting effects. However, one explanation may be that a variety of factors could be involved. Smyth and Pennebaker (2008) state that writing may force these individuals to label and acknowledge their emotional experiences. They hypothesize that labeling and acknowledging their experiences may lead to "more complex cognitive representation of the event and surrounding emotions, which, in-turn, may affect working memory" (p. 3). They also state that emotional changes are occurring as well. Labeling and acknowledging emotional experiences may change the way the person views herself, especially if she already has a distorted body image. Another explanation may be that writing about different experiences, rather than keeping them "bottled up" inside also makes the person feel better emotionally. While it is unclear why the writing intervention works, the interaction of a variety factors could be the explanation.

The American Psychiatric Association (2000) includes "a disturbance in perception of body shape and weight" (p. 583) as an essential feature of both anorexia and bulimia. Since this study showed that women with higher levels of eating disorder symptomatology had an improvement in body image after a writing task, then perhaps this paradigm can be used with women with eating disorders. Perhaps writing would help women with eating disorders also have an improvement in their body image, and this intervention can be used as part of the comprehensive treatment that is already used for women with eating disorders. Also, since this study showed that this writing intervention was beneficial and improved body image perceptions for those women with high eating disorders symptomatology, then perhaps this type of intervention could be used as a preventative measure for women who are symptomatic but do not have serious enough symptoms to be diagnosed with an eating disorder. Perhaps this writing intervention, as a part of a more comprehensive therapy, could help prevent more teenagers and women from developing serious and life-threatening eating disorders.

Despite the merits of this study, there were some limitations. One limitation of this study was that a self-report questionnaire was used to separate asymptomatic and symptomatic women, and it is impossible to determine if these women answered dishonestly on the questionnaire and were categorized into the wrong group. However, based on past research (Thompson \& Thompson, 1986), this questionnaire method is the best way to separate women into these two groups. A second limitation was that BMI was only calculated at the beginning of the study, not at each time that the body image questionnaire was given to the participants. Since the study was relatively short (approximately a month and a half long), it was assumed that BMI would not change drastically for participants. Therefore, a change in the mean rating for current figure should represent a change in perception of body image rather than an actual change in body weight. A third limitation was that the true cutoff score (20) on the EAT-26 could not be used because of the small number of participants who met that cutoff. Instead, a median split, with a median of 7 , had to be used to separate women into the high and low symptom groups. Because of the low number of participants in this study, this median split was the best option; however, future researchers should try to get more participants so that the true cutoff score of 20 could be used to separate participants into symptom groups. Finally, a fourth limitation was that all of the participants in this study were female college students between the ages of 18 and 45 in central Texas. Future research should seek to replicate these findings with participants from other geographic regions and from a diverse range of cultural backgrounds. 


\section{Summary and Conclusions}

Misperception or distortion of body image is so often associated with eating disorders that the American Psychiatric Association (2000) includes it as an essential feature of both anorexia and bulimia. Previous studies reveal that women overestimate their body size and often view their current figure as larger than what they view as the ideal female figure (Fallon \& Rozin, 1985; Lokken et al., 2003; Rand \& Wright, 2000; Rozin \& Fallon, 1988). Although past research also indicates that expressive writing has helped individuals with a variety of psychological and physical problems (Eels, 2006; Graf et al., 2008; Kallay \& Baban, 2008; Klein \& Boals, 2001; Kuiken et al., 2008; Low et al., 2010; Pachankis \& Goldfried, 2010; Pennebaker et al., 1990; Pennebaker et al., 1987; Pennebaker et al., 1988; Slatcher \& Pennebaker, 2006; Sloan et al., 2009; Sloan et al., 2008; Smyth et al., 2008; Spera et al., 1994; Yogo \& Fujihara, 2008), there have been few studies investigating the use of expressive writing tasks for improvement in body image. The research that has been conducted on this topic (e.g., Earnhardt et al., 2002; Frayne \&Wade, 2006; Grasso, 2007; Hiltunen, 2008; Schmidt et al., 2002) has not shown similar results to previous studies, that expressive writing groups improve more than factual writing groups.

This study showed similar results to past research on expressive writing and body image (Earnhardt et al., 2002; Frayne \& Wade, 2006; Grasso, 2007; Hiltunen, 2008), at least in the high symptomatology group. These women had an improvement in body image, regardless of writing group. Their mean rating of the figure that they believe they look like currently decreased and moved closer to the mean rating of the figure that they believe is ideal. This finding shows that writing (whether it is factual or expressive) may be beneficial for women who have eating disorder symptoms or a distorted body image. The women in the low symptomatology group did not show the same pattern, which makes sense because these women should not have a distorted body image. Also, the mean ratings for the figure deemed as the ideal and the figure deemed as the one that men would most prefer were not significantly changed by the writing intervention. These findings also make sense because women today are basically brainwashed by the media and told what the ideal woman should look like and what body shape men "should" prefer. So, although this study failed to show a change in the mean ratings for the ideal figure or the figure deemed as the one that men would most prefer, the fact that the mean rating for the current figure decreased and got closer to the mean rating of the ideal figure for women with high eating disorder symptomatology shows that writing may be beneficial and help improve body image in women who have a distorted body image or show early signs of an eating disorder.

\section{References}

American Psychiatric Association (2000). Diagnostic and Statistical Manual of Mental Disorders (4 ${ }^{\text {th }}$ ed.). Washington DC: American Psychiatric Association.

Bergstrom, R. L., Neighbors, C., \& Lewis, M. A. (2004). Do Men Find “Bony” Women Attractive? Consequences of Misperceiving Opposite Sex Perceptions of Attractive Body Image. Body Image, 1, 183-191.

http://dx.doi.org/10.1016/S1740-1445(03)00025-1

Button, E. J., \& Whitehouse, A. (1981). Subclinical Anorexia Nervosa. Psychological Medicine, 11, 509-516. http://dx.doi.org/10.1017/S003329170005282X

Earnhardt, J. L., Martz, D. M., Ballard, M. E., \& Curtin, L. (2002). A Writing Intervention for Negative Body Image: Pennebaker Fails to Surpass the Placebo. Journal of College Student Psychotherapy, 17, 19-35. http://dx.doi.org/10.1300/J035v17n01 04

Eels, J. E. (2006). Expressive Writing, Relationships, and Health. Unpublished Manuscript.

Fallon, A. E., \& Rozin, P. (1985). Sex Differences in Perceptions of Desirable Body Shape. Journal of Abnormal Psychology, 94, 102-105. http://dx.doi.org/10.1037/0021-843X.94.1.102

Frayne, A., \& Wade, T. D. (2006). A Comparison of Written Emotional Expression and Planning with Respect to Bulimic Symptoms and Associated Psychopathology. European Eating Disorders Review, 14, 329-340.

http://dx.doi.org/10.1002/erv.731

Garner, D. M., \& Garfinkel, P. E. (1979). The Eating Attitudes Test: An Index of the Symptoms of Anorexia Nervosa. Psychological Medicine, 9, 1-7. http://dx.doi.org/10.1017/S0033291700030762

Graf, M. C., Gaudiano, B. A., \& Geller, P. A. (2008). Written Emotional Disclosure: A Controlled Study of the Benefits of Expressive Writing Homework in Outpatient Psychotherapy. Psychotherapy Research, 18, 389-399. http://dx.doi.org/10.1080/10503300701691664

Grasso, K. M. (2007). An Expressive Writing Intervention for Body Image: A Randomized Controlled Trial. Unpublished 
Manuscript.

Gray, S. H. (1977). Social Aspects of Body Image: Perception of Normalcy of Weight and Affect of College Undergraduates. Perceptual and Motor Skills, 45, 1035-1040. http://dx.doi.org/10.2466/pms.1977.45.3f.1035

Hiltunen, L. M. (2008). The Psychological and Physical Effects of Expressive Writing in Individual with Binge Eating Tendencies. Unpublished Manuscript.

Johnson-Sabine, E., Wood, K., Mann, A., \& Wakeling, A. (1985). A Study of the Association of Current Social Pressures with Abnormal Eating Attitudes. International Journal of Eating Disorders, 4, 101-106.

http://dx.doi.org/10.1002/1098-108X(198502)4:1<101::AID-EAT2260040111>3.0.CO;2-J

Kallay, E., \& Baban, A. (2009). Emotional Benefits of Expressive Writing in a Sample of Romanian Female Cancer Patients. Cognition, Brain, Behavior, 12, 115-129.

Klein, K., \& Boals, A. (2001). Expressive Writing Can Increase Working Memory Capacity. Journal of Experimental Psychology: General, 130, 520-533. http://dx.doi.org/10.1037/0096-3445.130.3.520

Kuiken, D., Dunn, S., \& LoVerso, T. (2008). Expressive Writing about Dreams that Follow Trauma and Loss. Dreaming, 18, 77-93. http://dx.doi.org/10.1037/1053-0797.18.2.77

Lokken, K., Ferraro, F. R., Kirchner, T., \& Bowling, M. (2003). Gender Differences in Body Size Dissatisfaction among Individuals with Low, Medium, or High Levels of Body Focus. The Journal of General Psychology, 130, 305-310. http://dx.doi.org/10.1080/00221300309601161

Low, C. A., Stanton, A. L., Bower, J. E., \& Gyllenhammer, L. (2010). A Randomized Controlled Trial of Emotionally Expressive Writing for Women with Metastatic Breast Cancer. Health Psychology, 29, 460-466. http://dx.doi.org/10.1037/a0020153

Pachankis, J. E., \& Goldfried, M. R. (2010). Expressive Writing for Gay-Related Stress: Psychosocial Benefits and Mechanisms Underlying Improvement. Journal of Consulting and Clinical Psychology, 78, 98-110. http://dx.doi.org/10.1037/a0017580

Pennebaker, J. W., Colder, M., \& Sharp, L. K. (1990). Accelerating the Coping Process. Journal of Personality and Social Psychology, 58, 528-537. http://dx.doi.org/10.1037/0022-3514.58.3.528

Pennebaker, J. W., Hughes, C. F., \& O’Heeron, R. C. (1987). The Psychophysiology of Confession: Linking Inhibitory and Psychosomatic Processes. Journal of Personality and Social Psychology, 52, 781-793. http://dx.doi.org/10.1037/0022-3514.52.4.781

Pennebaker, J. W., Kiecolt-Glaser, J. K., \& Glaser, K. (1988). Disclosure of Traumas and Immune Function: Health Implications for Psychotherapy. Journal of Consulting and Clinical Psychology, 56, 239-245.

http://dx.doi.org/10.1037/0022-006X.56.2.239

Pulvers, K. M., Lee, R. E., Kaur, H., Mayo, M. S., Fitzgibbon, M. L., Jeffries, S. K., Butler, J., Hou, Q. J., \& Ahluwalia, J. S. (2004). Development of a Culturally Relevant Body Image Instrument among Urban African Americans. Obesity Research, 12, 1641-1651. http://dx.doi.org/10.1038/oby.2004.204

Rand, C. S. W., \& Wright, B. A. (2000). Thinner Females and Heavier Males: Who Says? A Comparison of Female to Male Ideal Body Sizes across a Wide Age Span. International Journal of Eating Disorders, 29, 45-50. http://dx.doi.org/10.1002/1098-108X(200101)29:1<45::AID-EAT7>3.0.CO;2-I

Rozin, P., \& Fallon, A. (1988). Body Image, Attitudes to Weight, and Misperceptions of Figure Preferences of the Opposite Sex: A Comparison of Men and Women in Two Generations. Journal of Abnormal Psychology, 97, 342-345. http://dx.doi.org/10.1037/0021-843X.97.3.342

Schmidt, U., Bone, G., Hems, S., Lessem, J., \& Treasure, J. (2002). Structured Therapeutic Writing Tasks as an Adjunct to Treatment in Eating Disorders. European Eating Disorders Review, 10, 299-315. http://dx.doi.org/10.1002/erv.465

Siervo, M., Boschi, V., Papa, A., Bellini, O., \& Falconi, C. (2005). Application of the SCOFF, Eating Attitudes Test 26 (EAT-26), and Eating Inventory (TFEQ) Questionnaires in Young Women Seeking Diet Therapy. Eating and Weight Disorders, 10, 76-82. http://dx.doi.org/10.1007/BF03327528

Slatcher, R. B., \& Pennebaker, J. W. (2006). How Do I Love Thee? Let Me Count the Words. Psychological Science, 17, 660-664. http://dx.doi.org/10.1111/j.1467-9280.2006.01762.x

Sloan, D. M., Feinstein, B. A., \& Marx, B. P. (2009). The Durability of Beneficial Health Effects Associated with Expressive Writing. Anxiety, Stress, and Coping, 22, 509-523. http://dx.doi.org/10.1080/10615800902785608

Sloan, D. M., Marx, B. P., Epstein, E. M., \& Dobbs, J. L. (2008). Expressive Writing Buffers against Maladaptive Rumination. Emotion, 8, 302-306. http://dx.doi.org/10.1037/1528-3542.8.2.302

Smyth, J. M., \& Pennebaker, J. W. (2008). Exploring the Boundary Conditions of Expressive Writing: In Search of the Right Recipe. British Journal of Health Psychology, 13, 1-7. http://dx.doi.org/10.1348/135910707X260117

Smyth, J. M., Hockemeyer, J. R., \& Tulloch, H. (2008). Expressive Writing and Post-Traumatic Stress Disorder: Effects on 
Trauma Symptoms, Mood States, and Cortisol Reactivity. British Journal of Health Psychology, 13, 85-93. http://dx.doi.org/10.1348/135910707X250866

Spera, S. P., Buhfreind, E. D., \& Pennebaker, J. W. (1994). Expressive Writing and Coping with Job Loss. Academy of Management Journal, 37, 722-733. http://dx.doi.org/10.2307/256708

Straub, R. O. (2007). Health Psychology: A Biopsychosocial Approach. New York: Worth Publishers.

Stunkard, A. J., Sorensen, T., \& Schulsinger, F. (1983). Use of the Danish Adoption Register for the Study of Obesity and Thinness. Research Publications-Association for Research in Nervous \& Mental Disease, 60, 115-120.

Thompson, J. K., \& Thompson, C. M. (1986). Body Size Distortion and Self-Esteem in Asymptomatic, Normal Weight Males and Females. International Journal of Eating Disorders, 5, 1061-1068. http://dx.doi.org/10.1002/1098-108X(198609)5:6<1061::AID-EAT2260050609>3.0.CO;2-C

Thompson, M. G., \& Schwartz, D. M. (1982). Life Adjustment of Women with Anorexia Nervosa and Anorexia-Like Behavior. International Journal of Eating Disorder, 1, 47-60. http://dx.doi.org/10.1002/1098-108X(198224)1:2<47::AID-EAT2260010203>3.0.CO;2-W

Williams, R. L., Schaefer, C. A., Shisslak, C. M., Gronwaldt, V. H., \& Comerci, G. D. (1986). Eating Attitudes and Behaviors in Adolescent Women: Discrimination of Normals, Dieters, and Suspected Bulimics Using the Eating Attitudes Test and Eating Disorder Inventory. International Journal of Eating Disorders, 5, 879-894. http://dx.doi.org/10.1002/1098-108X(198607)5:5<879::AID-EAT2260050509>3.0.CO;2-8

Yogo, M., \& Fujihara, S. (2008). Working Memory Capacity Can be Improved by Expressive Writing: A Randomized Experiment in a Japanese Sample. British Journal of Health Psychology, 13, 77-80.

http://dx.doi.org/10.1348/135910707X252440 